\title{
Role of Ultrasound in Determining the Severity of Hallux Valgus: Ultrasonic Characteristics of Abductor Hallucis Muscle
}

\author{
Elham Neshan ${ }^{1}$, Mohammad Bagheri Bidhendy ${ }^{2 \bowtie}$ \\ ${ }^{1}$ Department of Radiology, Islamic Azad University, Tehran Medical Sciences Branch, Tehran, Iran \\ ${ }^{2}$ Students' Research Committee, Islamic Azad University, Tehran Medical Sciences Branch, Tehran, Iran
}

\section{Dear Editor,}

$\mathrm{H}$ allux Valgus is a forefoot deformity involving progressive lateral deviation of the hallux and medial deviation of the first metatarsal resulting in a medial prominence at the first metatarsophalangeal joint [1]. Such a deformity is more common in older population with estimated prevalence of $36 \%$ in those over 65 , while the prevalence rate in adults between 18 and 65 years is $23 \%$ [2]. Although the deformity may remain asymptomatic, it has been associated with cosmetic appearance concerns, pain and reduced health-related quality of life [3].

Previous studies introduced some risk factors, which involve hallux valgus including increasing age, being female, a positive family history of hallux valgus, abnormal hind foot kinematics, wearing high heels or tight footwear [4-6]. Bony abnormalities (roundshaped first metatarsal head, long first metatarsal, bipartite medial sesamoids) and muscular abnormalities (accessory extensor hallucis longus tendon and accessory tibialis posterior tendon) have also been linked to the deformity [7-9].

Despite the involvement of abductor hallucis muscle in the pathomechanics of this deformity, a limited number of studies have investigated the abductor hallucis muscle with hallux valgus [4]. Although studies indicated that the computed tomography and magnetic

\section{GMJ}

2015 Galen Medical Journal

Fax: +98 7312227091

PO Box 7461686688

Email:info@gmj.ir resonance imaging as well as EMG are the choice tools in the evaluation of musculoskeletal disorders [9], evidence has also shown that ultrasound proves similar validity to EMG and manual muscle testing in assessing neuromuscular pathologies in extrinsic and intrinsic foot muscles with an added advantage in its ability to visualize muscle atrophy [10]. Hence, the aim of this study is to employ musculoskeletal ultrasound to determine significant differences between dorsoplantar (DP) thickness, medio-lateral (ML) width and cross-sectional area (CSA) of the abductor hallucis muscle among different severities of hallux valgus.

This cross-sectional study was performed on 50 participants aged over 20 years attending Boo-Ali hospital in Tehran, Iran from April 2014 to April 2015. The study was approved by the ethical committee of Azad University and written informed consent for participation was obtained. Exclusion criteria included history of foot or ankle surgery, current trauma to the foot and ankle, a neuromuscular condition or a diagnosis of inflammatory arthritis or diabetes mellitus. Hallux valgus was measured using Manchester Scale which utilizes four photographs of increasing severity of hallux valgus (Figure1). This tool has been shown to have excellent reliability and validity in both clinical assessment and self-assessment of hallux valgus [2]. The scale is graded 0 for no deformity, 1 for mild deformity, 2 for moder-

\footnotetext{
Correspondence to:

Mohammad Bagheri Bidhendy, Medical Research Center, Azad University, Tehran Medical Branch, Attarimoqaddam Ave, Haqani Ave, Dr. Shariati St, Tehran, Iran Telephone Number: +9821-22006660

Email Address: mbb313@gmail.com
} 
ate deformity and 3 for severe deformity [2]. The researcher observed each participant in relaxed weight-bearing stance to determine which one of the four Manchester Scale photographs best represented the degree of hallux valgus deformity. ALOKA SSD 3500 Ultrasound System (Tokyo, Japan) with a $50 \mathrm{~mm}$ linear probe of $7.5 \mathrm{MHz}$ was used to obtain images of the abductor hallucis muscle belly. The researcher underwent 3 months of training in performing ultrasound scans prior to data collection. The ultrasound machine has been shown to produce reliable images of the abductor hallucis muscle for the purpose of measuring ML width,DP thickness and CSA [1].A similar procedure to that outlined by Stewart[1]was used by the researcher to obtain ultrasound images in the current study. This involved the participant being instructed to fully relax in a seated position with the legs extended. The foot to be measured was positioned with the ankle at neutral(i.e. $0^{\circ}$ ). The knees were supported in approximately $15^{\circ}$ of flexion with the involved leg in a comfortable degree of external rotation to optimize the researcher's access to the medial foot during scanning. The researcher palpated the medial malleolus and using a ruler drew a line anterior to this bony landmark in an inferior direction. Parker Aquasonic W 100 Ultrasound Transmission Gel (Fairfield, USA) was applied along this drawn line to optimize skin-probe contact whilst avoiding compression of the muscle. The probe was positioned perpendicular to the drawn line. Three repetitive images were obtained for each foot and a mean value was calculated. A 30 second rest was allowed between each image capture in which the probe was placed back in its holder. Each image was analyzed to obtain measurements for DP thickness (mm), ML width $(\mathrm{mm})$ and CSA (mm2) (Figure2). One-way ANOVA and post hoc were used for statistical analysis; all tests were done via SPSS statistical software (16, USA). $\mathrm{P}$ value $\leq 0.05$ was considered statistically significant.The mean age of patients was $48.3 \pm 18.04$ years. The mean BMI of participants was $28.07 \pm 3.99$ $\mathrm{kg} / \mathrm{m} 2$. Twenty-seven patients have grade 1 , 20 patients and 3 patients have grade 2 and 3 , respectively. Considering Table 1, there
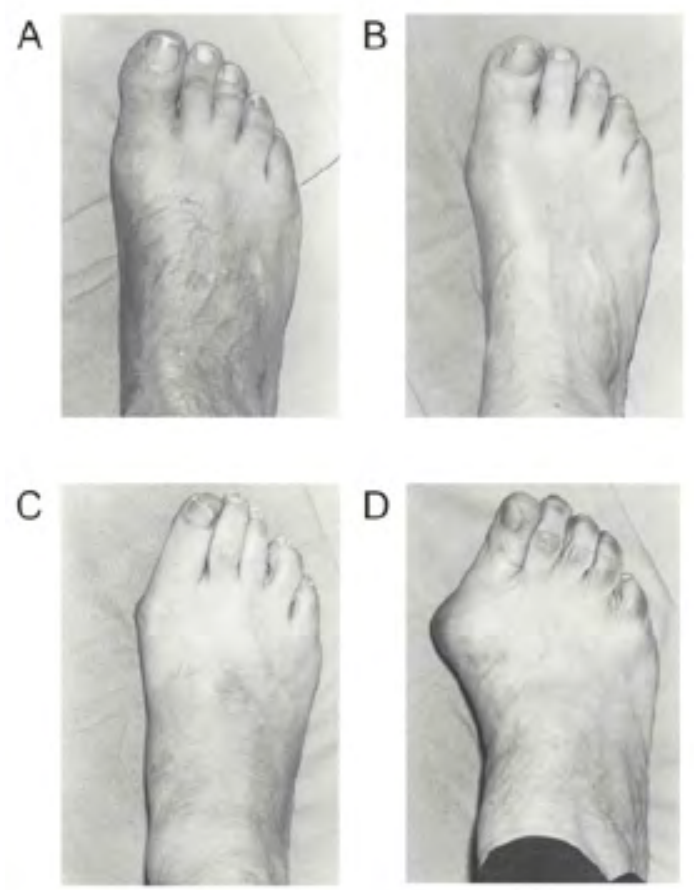

Figure1. Manchester Scale photographs, The scale is graded 0 'no deformity (A), 1'mild deformity (B), 2'moderate deformity $(C)$ and 3'severe deformity (D).

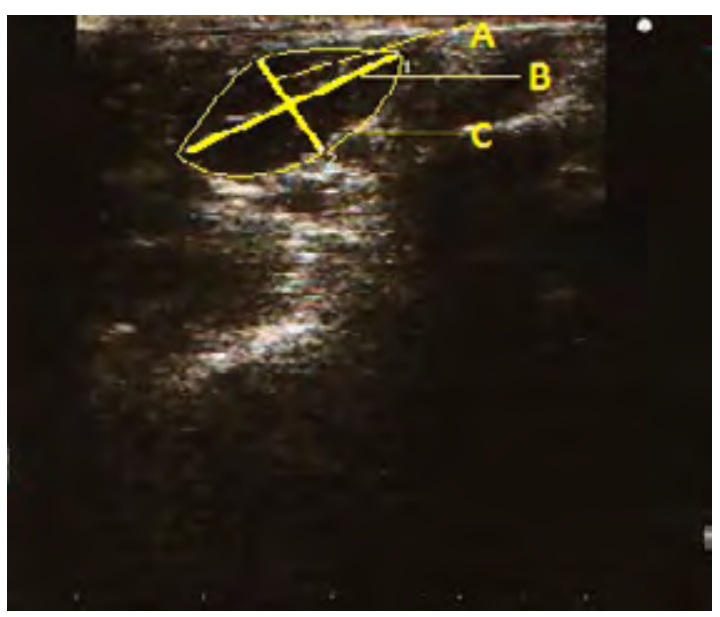

Figure2. Abductor Hallucis Characteristic Measurements with Ultrasound, A: DP thickness; B: ML width; C: CSA.

were significant correlations between DP and ML thickness and hallux valgus grade. In addition, there were significant correlations between hallux valgus grade and increasing age. However, there were no significant differences in the term CSA and BMI ( $\mathrm{P}>0.05)$. 
Table 1. Correlation between Abductor Halluces Muscle Characteristics and Hallux Valgus Severity. Data are presented as mean \pm SD.

\begin{tabular}{cccc}
\hline & $\begin{array}{c}\text { DP thickness } \\
(\mathbf{m m})\end{array}$ & $\begin{array}{c}\text { ML thickness } \\
(\mathbf{m m})\end{array}$ & $\begin{array}{c}\text { CSA } \\
\left(\mathbf{m m}^{2}\right)\end{array}$ \\
\hline Grade 1 & $8.82 \pm 2.15^{*}$ & $20.44 \pm 3.76^{*}$ & $126.15 \pm 47.11$ \\
Grade 2 & $7.8 \pm 1.56^{*}$ & $17.44 \pm 3.76^{*}$ & $103.9 \pm 34.27$ \\
Grade 3 & $6.5 \pm 0.55^{*}$ & $15.9 \pm 2.42^{*}$ & $99.33 \pm 2.51$ \\
\hline
\end{tabular}

${ }^{*} \mathrm{P}<0.05$ in the group

In the present study, results showed increasing age associated with an increasing risk of hallux valgus. Stewart et al. study showed increase in age also increases the risk of hallux valgus. The age as a risk factor for the development of hallux valgus has been suggested [1]. In addition, they noticed that abductor hallucis muscle characteristic size (MD, DP and CSA) that is consistent with the results of our study. Cameron et al reported that sonography could be applied to evaluate the abductor hallucis muscle in the patients who suffer from hallux valgus [7]. Finally, regarding the results of the present study and previous reports, the role of sonographic findings, this method can be further evaluated for its positive impacts on the patients suffering from hallux valgus diseases.

Keywords: Hallux Valgus; Abductor Hallucis; Manchester Scale; Bunion Deformity

\section{References}

1. Stewart S, Ellis R, Heath M, Rome K. Ultrasonic evaluation of the abductor hallucis muscle in hallux valgus: a cross-sectional observational study. BMC Musculoskelet Disord. 2013; 14: 45.

2. Nix S, Smith M, Vicenzino B. Prevalence of hallux valgus in the general population: a systematic review and meta-analysis. $\mathrm{J}$ Foot Ankle Res. 2010; 3: 21.

3. Menz HB, Morris ME. Footwear characteristics and foot problems in older people. Gerontology. 2005;51(5):346-51.

4. D'Arcangelo PR, Landorf KB, Munteanu SE, Zammit GV, Menz HB. Radiographic correlates of hallux valgus severity in older people. J Foot Ankle Res. 2010; 3: 20.

5. Lee KM, Ahn S, Chung CY, Sung KH, Park MS. Reliability and Relationship of Radiographic Measurements in Hallux Valgus. Clin Orthop Relat Res. 2012; 470(9): 2613-21.

6. Mann RA, Coughlin MJ. Hallux valgus--etiology, anatomy, treatment and surgical considerations. Clin Orthop Relat Res. 1981;(157):31-41.
7. Cameron AFM, Rome K, Hing WA. Ultrasound evaluation of the abductor hallucis muscle: Reliability study. J Foot Ankle Res. 2008; 1: 12.

8. Nguyen US, Hillstrom HJ, Li W, Dufour AB, Kiel DP, Procter-Gray E, et al. Factors associated with hallux valgus in a population-based study of older women and men: the MOBILIZE Boston Study. Osteoarthritis Cartilage. 2010;18(1):41-6.

9. Hamidi S, Fahimi N, Jangholi E, Fahimi MA, Farshad A, Foroushani FN, et al. Evaluation of Adjacent Segment Degeneration after Cervical Spine Surgery: Arthroplasty Versus Fusion. GMJ. 2013;2(1):12-7.

10. Roddy E, Zhang W, Doherty M. Prevalence and associations of hallux valgus in a primary care population. Arthritis Rheum. 2008;59(6):857-62. 